\title{
Novel Method for Breakthrough Removal of Azo Dye from Aqueous Environment Using Integrated Coagulation and Fenton Process
}

\author{
Sherine Awad ${ }^{1}$ and Usama Eldemerdash ${ }^{2}$ \\ ${ }^{1}$ Department of Basic Sciences, Faculty of Engineering, Benha University, Benha 13512, Egypt \\ ${ }^{2}$ Department of Chemical Engineering, Universiti Teknologi Petronas, Tronoh, 31750 Perak, Malaysia
}

Correspondence should be addressed to Usama Eldemerdash; usama59@gmail.com

Received 21 December 2013; Revised 3 March 2014; Accepted 4 March 2014; Published 27 March 2014

Academic Editor: Shinya Maenosono

Copyright (C) 2014 S. Awad and U. Eldemerdash. This is an open access article distributed under the Creative Commons Attribution License, which permits unrestricted use, distribution, and reproduction in any medium, provided the original work is properly cited.

\begin{abstract}
Fenton process has proven to be efficient in the removal of color and chemical oxygen demand (COD) from the aqueous environment. However, the environment, health, and economic constraints on the dosage of hydrogen peroxide represent a limitation towards a wide practical use of this approach. In this study, a novel approach is proposed; this includes the treatment with ferrous oxide through coagulation followed by integrated Fenton process. However, the excess ferrous and ferric ions from the coagulation step were utilized in the advanced oxidation step using hydrogen peroxide. The advantage here is the usage of the minimum number of hydrogen peroxide to comply with all the international environmental, safety, and health regulations. The aim of this study is to evaluate the capabilities of the unique integrated process of coagulation and Fenton process for color and COD removal of azo dye in an aqueous environment. The optimum operating parameters such as coagulant dose, temperature, and the dose of hydrogen peroxide were determined. This was done with the objective to optimize the percentage removal of color and COD. The main properties of the treated wastewater such as $\mathrm{pH}$ and COD content were measured after treatment against the Malaysian standard part B. The results show that the proposed method was successful for the removal of the color and COD from the aqueous environment to reach more than $99 \%$ with the new method.
\end{abstract}

\section{Introduction}

Textile wastewater includes a large variety of dyes and chemicals, which represent a challenge to meet the environmental regulations [1]. The major attributes of pollution to be treated in the textile wastewater are suspended solids, chemical oxygen demand (COD), color, and dissolved solids [2]. Table 1 shows the details of these characteristics. Polyvinyl alcohol (PVA) and dyestuff are the main components of refractory organic compounds and color containing substances from textile dyeing process [3].

Current methods of treating textile wastewaters often have problems with the efficiency; this is due to the existence of reactive dyestuff and other organic compounds which are refractory to oxidants [4]. Furthermore, the secondary effluent of the textile wastewater has been reported to have a ratio of biochemical oxygen demand (BOD) to chemical oxygen demand (COD) lower than 0.1 and color removal efficiency of only 10-20\% [1]. However, the composition of the effluent is very complicated; it has salts, surfactants, mineral oils, and heavy metals [5]. This addresses the serious need for efficient process for effective removal of COD and color from the textile effluent. Fenton process employs ferrous ion and hydrogen peroxide $\left(\mathrm{H}_{2} \mathrm{O}_{2}\right)$ to generate the radical hydroxyl $\left(\mathrm{OH}^{-}\right)$. The reaction turns the ferrous ion into ferric ion, which is a type of coagulant $[6,7]$. Since both ferric and ferrous ions are coagulants, the Fenton process can have a dual task, which are oxidizing and coagulating the particle in textile effluent. Fenton process is capable of decolorizing textile wastewater with an oxidation time of $20-40 \mathrm{~min}[8,9]$ and $85 \%$ removal of COD in $40-120 \mathrm{~min}$ $[10,11]$. Both the PVA and dyestuff are high molecular weight compounds. In terms of operating cost, it is not feasible to treat these compounds with the Fenton process due to 
TABLE 1: Characteristics of textile wastewater.

\begin{tabular}{lc}
\hline Parameters & Values \\
\hline $\mathrm{pH}$ & $7.0-9.0$ \\
Biochemical oxygen demand (mg/L) & $80-6000$ \\
Chemical oxygen demand (mg/L) & $150-12000$ \\
Total suspended solid (mg/L) & $15-8000$ \\
Total dissolved solid (mg/L) & $2900-3100$ \\
Chloride (mg/L) & $1000-1600$ \\
Total Kjeldahl nitrogen (mg/L) & $70-80$ \\
Color (Pt-Co) & $50-2500$ \\
\hline
\end{tabular}

the considerable dosages of ferrous ions and hydrogen peroxide required [12]. Although standalone coagulation process can remove the color content, however, it is not efficient enough to remove COD to meet the environmental regulation. On the other side, standalone advanced oxidation process is very efficient in the removal of COD, but it has the limitation of the amount of oxidation reagent such as hydrogen peroxide. This is due to the environment and health constraints on the dosage of hydrogen peroxide, which represents a limitation towards a practical use of this approach. This study aims to solve this dilemma and to propose a new method for breakthrough removal of azo dye stuff from the aqueous environment.

1.1. Hydrogen Peroxide Exposure Limits and Toxicity. The current Occupational Safety and Health Administration (OSHA) permissible exposure limit (PEL) for hydrogen peroxide is 1 part per million (ppm) parts of air, 1.4 milligrams per cubic meter $\left(\mathrm{mg} / \mathrm{m}^{3}\right)$ as an 8-hour time-weighted average (TWA) concentration [13]. The National Institute for Occupational Safety and Health (NIOSH) has established a recommended exposure limit (REL) for hydrogen peroxide of $1 \mathrm{ppm}$ as a TWA for up to a 10-hour workday and a 40-hour workweek [14]. The American Conference of Governmental Industrial Hygienists (ACGIH) has assigned hydrogen peroxide a threshold limit value (TLV) of $1 \mathrm{ppm}$ as a TWA for a normal 8-hour workday and a 40-hour workweek [14]. The $\mathrm{NIOSH}$ limit is based on the risk of eye, mucous membrane, and skin irritation [14]. One of the terrifying examples of overdose of hydrogen peroxide is about a 16-month-old boy who was found playing with an empty bottle that had contained about $230 \mathrm{~g}$ of $3 \%$ hydrogen peroxide solution. The container had a cracked lid that allowed the contents to be sucked. White foam emerged from the child's mouth and nose. He then walked to bed and was found dead 10 hours later. In a postmortem examination, there was frothy blood in the right ventricle of the heart and the portal venous system. The gastric mucosa was red and the brain oedematous. Histopathological examination showed oedema in the lungs, and diffuse interstitial emphysema was evident. Gas emboli were found within the pulmonary vasculature and gastric and intestinal lymphatics. Clear vacuoles were also found within the walls of the gastrointestinal tract, in the spleen, kidney, and myocardium [15]. The estimated dose of hydrogen peroxide ingested was $7 \mathrm{~g}$, about $600 \mathrm{mg} / \mathrm{kg} / \mathrm{bw}$ for a boy of $11.6 \mathrm{~kg}$ [14].

\section{Experiment and Materials}

Azo dyes have been used extensively in textile, leather, cosmetic, and paper industries. Azoic dyes are dyes that contain a double bond of nitrogen in their structure. Figure 1 shows the structure of Erichrome Black T. Normally, the color is determined through their azo bond, which is associated with chromophores and auxochromes. Auxochromes basically are group of atoms, which are attached to the chromophores and can be categorized into two major classes: acidic, $-\mathrm{COOH},-\mathrm{OH},-\mathrm{SO}_{3} \mathrm{H}$ and basic, $-\mathrm{NHR},-\mathrm{NR}_{2}$, $-\mathrm{NH}_{2}$. Meanwhile, chromophores are the molecules which are responsible towards the color, whereby color may arise when the molecules absorb a particular wavelength and reflect them. Briefly, the most active bond in this dyestuff is the azo bond itself, and the breakdown of this bond may lead to the decolorization of dyes effluent. The azo bond can be weakened or broken down through oxidation methods.

The concentration of the azo dye in textile effluent is lower than $500 \mathrm{ppm}$ [16]. However, throughout the experimental works of this study, a 400 ppm synthetic wastewater has been used. In order to prepare the synthetic wastewater, $1000 \mathrm{~mL}$ of distilled water was added to $400 \mathrm{mg}$ of Eriochrome Black T supplied by Systerm StainPur. Furthermore, calcium hydroxide of concentration of $0.1 \mathrm{M}$ was prepared to control the $\mathrm{pH}$ of the wastewater for different experiments. A standard jar test apparatus was implemented during the experimental works by varying a few parameters, namely, dosage of the inorganic coagulant which is ferrous sulphate (100 ppm$2500 \mathrm{ppm})$ and $\mathrm{pH}(5-11)$, and all of them are carried out at ambient temperature. The FC6S-VELP (Scientifica) jar test was principally equipped with six paddle stirrer, together with six beaker apparatus. For different operating temperature, Julabo SW22 shaking water bath was used to examine the effect of different temperatures within the range (30-80 degree $\left.{ }^{\circ} \mathrm{C}\right)$. Custom made jacketed beaker and UV lamp were used in the second section of the treatment, which includes Fenton reaction. A Phillips $250 \mathrm{~W}$ mercury lamp (wavelength of $420 \mathrm{~nm}$ ) was used. Figure 2 shows a schematic diagram of the photoreactor employed in the study.

The wastewater from coagulation treatment was treated further using hydrogen peroxide and UV to investigate the effect of Fenton reaction on COD and color removal. Each beaker used for the test contains $100 \mathrm{~mL}$ of sample wastewater. Prior to pouring the wastewater into the beaker, the sample wastewater was homogenous to ensure homogeneity of the sample. Then, the sample was measured for its COD, turbidity, color, and original $\mathrm{pH}$. During the experiment, the initial $\mathrm{pH}$ of the wastewater was controlled using lime $(\mathrm{CaOH})$ and sulphuric acid. After the coagulant had dosed into the wastewater, the batches were agitated with rapid mixing (200 ppm) for 10 minutes and slow mixing (45 rpm) for 30 minutes. Then, the suspension will be allowed to settle for one hour. Prior to measuring the COD, color, turbidity, and final $\mathrm{pH}$, the supernatant in each beaker was filtered with 


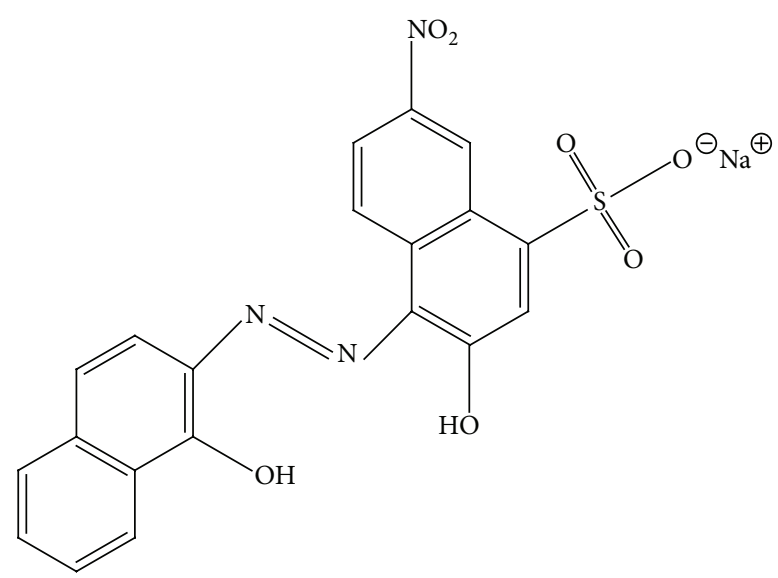

Figure 1: Chemical structure of Eriochrome Black T.

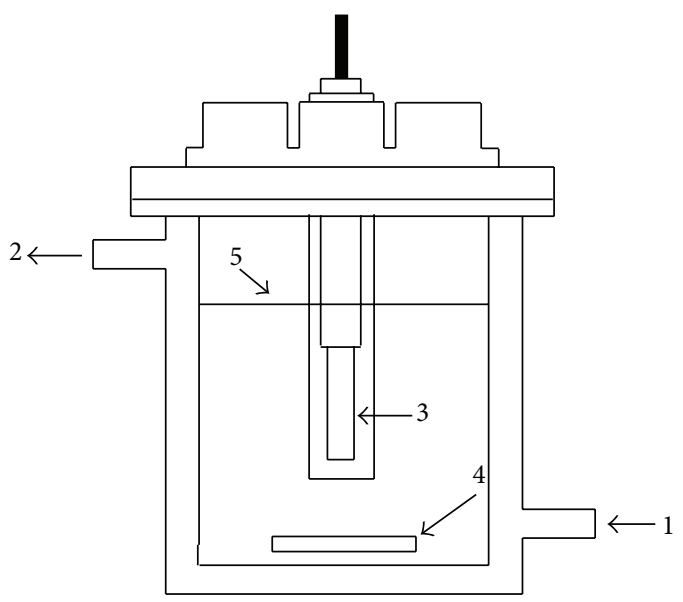

1: Water inlet

2: Water outlet

3: UV lamp

4: Magnetic stirring

5: Wastewater sample level

FIGURE 2: Schematic diagram of the photoreactor.

(Advantec) glass fiber filter and accomplished by the total suspended solid (TSS) apparatus. The reason for applying the TSS and drying apparatus is to measure the dried produced sludge during the experimental work. Even the wastewater sample that was treated by an oxidation process, the totally produced sludge was measured after the oxidation process. During the experimental work, the $\mathrm{pH}$ of the wastewater was measured and controlled using a bench $\mathrm{pH}$ meter model 510 manufactured by (Eutech Std.). Turbidity measurement was done using $\mathrm{HACH}(2100 \mathrm{P})$ portable turbidity meter in which the wastewater was placed into the sample cell and put into the instrument cell compartment for the measurement analysis. Meanwhile, COD and color were measured by using HACH Digital Reactor Block (DRB) 200 through coulometric for high range COD and color determination at the wavelength of $620 \mathrm{~nm}$. COD analysis involves two different steps, digestion and COD determination.

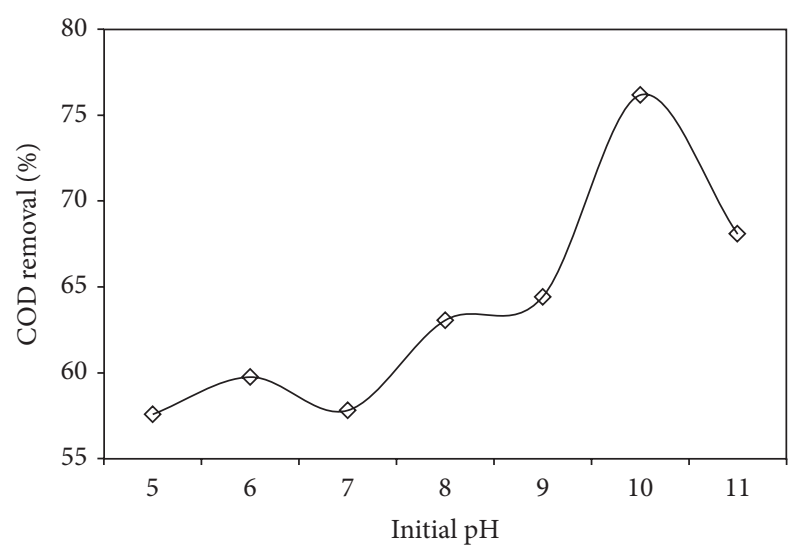

FIgure 3: Percentage of COD removal at different initial $\mathrm{pH}$.

\section{Results and Discussion}

\subsection{First Step Treatment with Coagulation}

3.1.1. Effect of $p H$. The initial $\mathrm{pH}$ for the synthetic wastewater was 4.90; this $\mathrm{pH}$ value was controlled by using slaked lime, $\mathrm{Ca}(\mathrm{OH})_{2}$ solution. The lime solution not only acts as $\mathrm{pH}$ controller but also as a coagulant aid. According to Kirns Chemical Ltd., a manufacturer of ferrous sulfate, the best $\mathrm{pH}$ for color removal using ferrous sulfate is 9.5 to 10.5 , but it may vary according to the dye stuff being removed. Therefore, the study of the effect of $\mathrm{pH}$ to this treatment is essential. In this study, different $\mathrm{pH}$ of wastewater was dosed with $1000 \mathrm{ppm}$ of ferrous sulfate at room temperature $\left(20^{\circ} \mathrm{C}\right)$. The influence of the color and COD removal, along with the final $\mathrm{pH}$ of the wastewater after treatment, was investigated. Figure 2 illustrates the highest COD removal to take place when the initial $\mathrm{pH}$ of the wastewater is 10 . The COD removal was raised within the $\mathrm{pH} 5$ to $\mathrm{pH} 10$ and declined at $\mathrm{pH} 11$. The percentage of COD removed at $\mathrm{pH} 10$ is $76.17 \%$, and the COD removal percentage is higher when the $\mathrm{pH}$ value is within the basic $\mathrm{pH}$ range as shown in Figure 3.

The percentage of color removal with different initial $\mathrm{pH}$ is shown in Figure 4. It shows a similar pattern with Figure 3, where the removal percentage is higher in basic $\mathrm{pH}$ range. As mentioned earlier, $\mathrm{Ca}(\mathrm{OH})_{2}$ acts as a $\mathrm{pH}$ controller as well as a coagulant aid, which increases the density and toughness of the floc formed after the coagulation process.

This may be influenced by two factors, which are the reactivity of ferrous sulfate under different $\mathrm{pH}$ and the amount of coagulant aid (lime) available at certain $\mathrm{pH}$ value. Coagulant aid is an essential factor for a successful coagulation process, where it strengthens the floc formed in the wastewater. It also reduces the time for settling process. The final $\mathrm{pH}$ of the wastewater after the treatment process was in the range 4.85 to 5.25. This phenomenon can be explained by the reaction of ferrous sulfate with alkalinity in the water that produced carbon dioxide which further reacts with water to produce carbonic acid, thus reducing the $\mathrm{pH}$ as follows:

$$
\mathrm{FeSO}_{4}+2 \mathrm{CaHCO}_{3} \longrightarrow \mathrm{Fe}(\mathrm{OH})_{2}+\mathrm{CaSO}_{4}+2 \mathrm{CO}_{2} \text {. }
$$




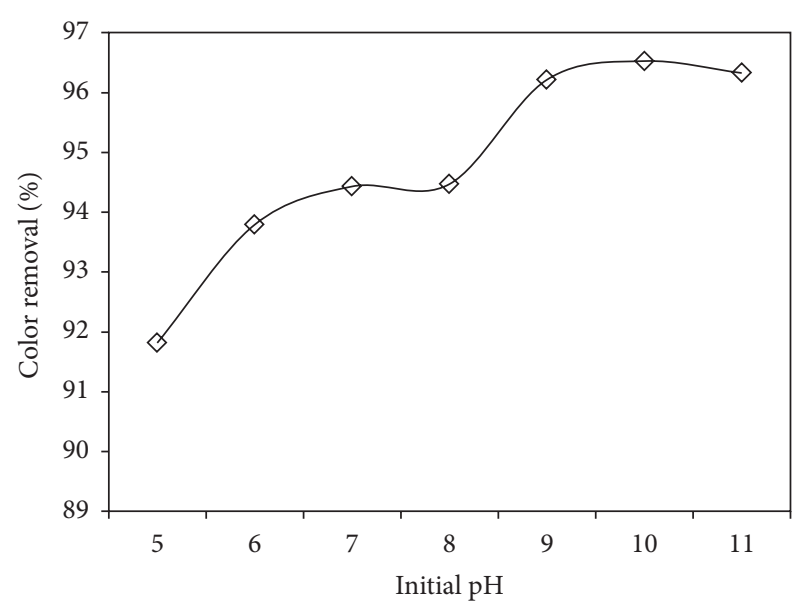

FIGURE 4: Percentage of color removal at different initial $\mathrm{pH}$.

The variation of $\mathrm{pH}$ plays an essential role in the coagulation process since it affects the charge on hydrolysis product and precipitation of metal hydroxides. The $\mathrm{pH}$ will bring impact towards the surfaces charge of the coagulant and also stabilization of the suspension. The $\mathrm{pH}$ should be adjusted to the optimum point, so that the coagulation will be more efficient, which enable the colloids or flocs to coalesce, thus will promote a better result in decolorization and COD removal.

3.1.2. Effect of Temperature. The effluent temperature has a negative influence on COD and color removal as shown in Figures 5 and 6 . It was observed that the treated wastewater color became darker with the increment of the operating temperature. Furthermore, disappearance of bigger colloidal particle was significant especially when the temperature is higher than $70^{\circ} \mathrm{C}$. This phenomenon can be explained by basic theory of kinetic energy. The higher the temperature is, the higher the particle's kinetic energy. High kinetic energy influences the particles to move faster, which results in the redissolving of the flocs into the water. This has a counter effect on the COD and color removal to be lower than at low temperatures, as shown in Figures 5 and 6.

3.1.3. Determination of Optimum Dosage. The experiment to find the optimum dosage of ferrous sulfate was performed at optimum conditions of $\mathrm{pH}$ and temperature. Coagulant dosage is one of the most critical parameters in determining the effectiveness of the treatment. Apart from getting the desired dye removal, the optimum dosage also allows minimization of operating cost as well as reducing the sludge accumulation during the treatment process. Figures 7 and 8 show the percentage of COD and color removal versus the amount of coagulant dosage, respectively. The experiment was performed at temperature of $20^{\circ} \mathrm{C}$, with the $\mathrm{pH}$ adjusted and controlled to be 10 . The lime solution has provided sufficient alkalinity to the wastewater so that the ferrous sulfate can react and form flocs with dye particles. The results show that the highest COD and color removal

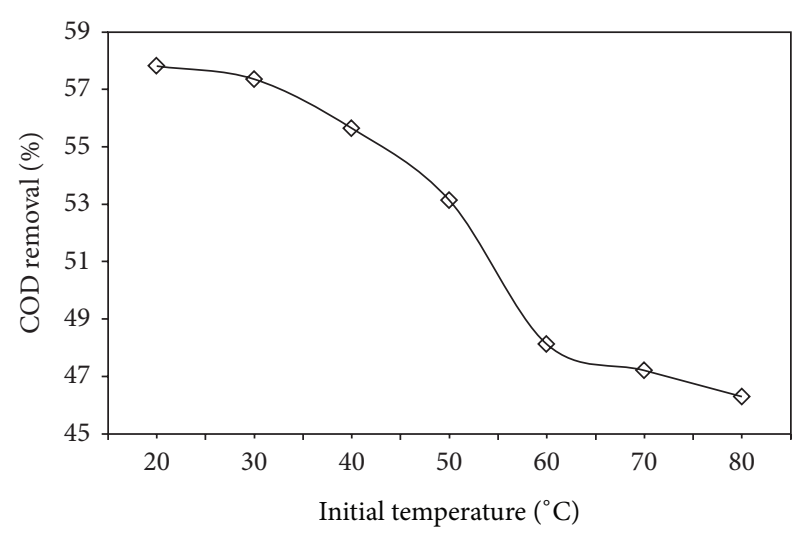

Figure 5: Percentage of COD removal at different operating temperature.

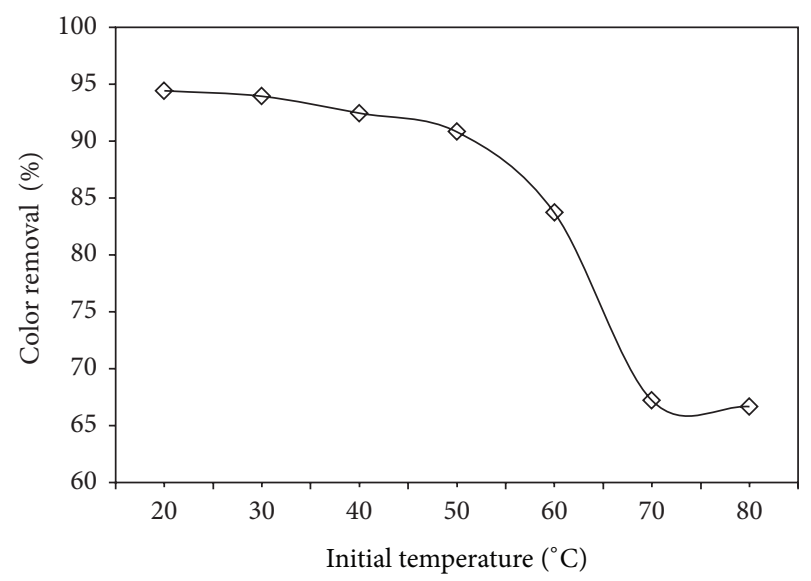

Figure 6: Percentage of color removal at different operating temperature.

happened at $1000 \mathrm{ppm}$ coagulant dosage. Above $1000 \mathrm{ppm}$ of coagulant dosage, the percentage of COD removal shows a significant reduction. The results show that, at 1250 and $1500 \mathrm{ppm}$ of coagulant dosage, the percentage of COD removal does not even achieve 75 percent. However, for the color removal, the recorded change at dosage above $1000 \mathrm{ppm}$ up to $1500 \mathrm{ppm}$ was not significant. The reduced performance of COD removal after the optimum point was caused by the excess coagulant which has been absorbed onto the colloidal surfaces.

Figure 9 shows the final $\mathrm{pH}$ of the treated wastewater, the $\mathrm{pH}$ reduced from 10 to the low range of 4.9 to 5.4. The reason for this phenomenon is the fact that the reaction of ferrous sulfate with alkalinity in the water produces carbon dioxide, which reacts further with water to produce carbonic acid. Figure 10 presents the amount of sludge accumulated in the process. The value was recorded after the sludge was collected and filtered. The sludge was then dried and weighed to get the total amount of solid precipitates.

The amount of sludge produced from this treatment ranges from 2 to $7 \mathrm{mg}$. The results show that the higher 


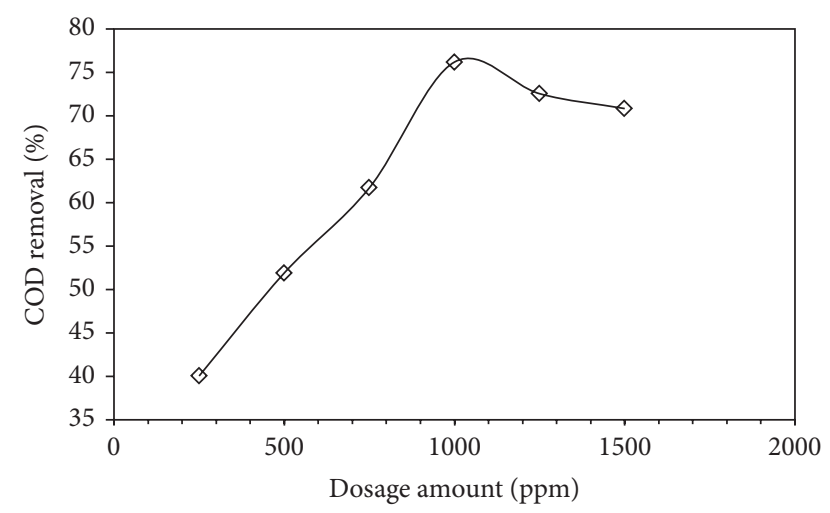

FIgURE 7: Percentage of COD removal at coagulant dosage.

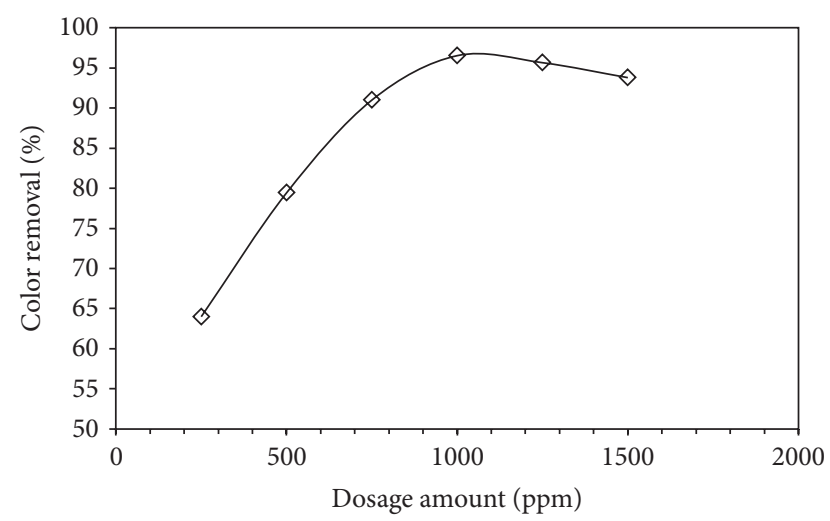

FIgURE 8: Percentage of color removal at different coagulant dosage.

the coagulant dosage, the higher amount of sludge it produces. The sludge production may be explained by the basic reaction of ferrous sulfates and lime itself, which produces iron hydroxides as the precipitates. The reaction has been simplified as follows:

$$
\mathrm{FeSO}_{4}+\mathrm{H}_{2} \mathrm{O}+\mathrm{Ca}(\mathrm{OH})_{2} \longrightarrow \mathrm{Fe}(\mathrm{OH})_{2}+\mathrm{H}_{2} \mathrm{O}+\mathrm{CaSO}_{4} \text {. }
$$

The optimum amount of coagulant does vary from one type of dye to the others. To solve this problem, integration with hydrogen peroxide process is proposed. The aim is to make a typical Fenton's oxidation process. Application of hydrogen peroxide really improves the effect of COD removal.

3.2. Second Step Treatment with Fenton Process. Hydrogen peroxide $\left(\mathrm{H}_{2} \mathrm{O}_{2}\right)$ was added to the effluent which resulted from the coagulation step with $1000 \mathrm{ppm}$ ferrous sulfate at $20^{\circ} \mathrm{C}$ and $\mathrm{pH} 10$. Hydrogen peroxide will be photolyzed by the UV ray to form two hydroxyl radicals $\left(2 \mathrm{OH}^{-}\right)$that will further react with the organic compound of the dye stuff. $\mathrm{H}_{2} \mathrm{O}_{2}$ also was found to be active in acidic $\mathrm{pH}$, which recorded to be the best at $\mathrm{pH}$ range 3 to 4 [19]. Since the wastewater has become acidic after the first treatment step, no further alteration of $\mathrm{pH}$ was made to the wastewater. The percentage of color removal was recorded to be in the range of $93.96 \%$ to $95.67 \%$ as shown in Figure 11 . All COD values

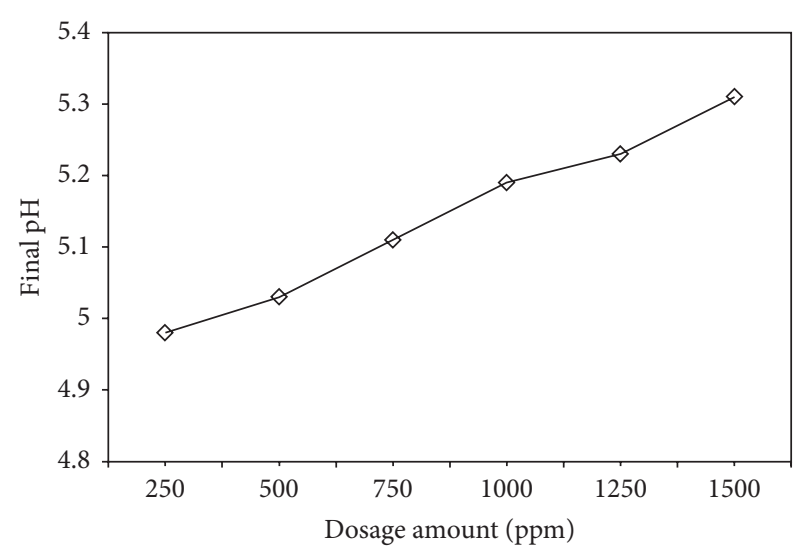

FIGURE 9: Final pH of the effluent at different coagulant dosage.

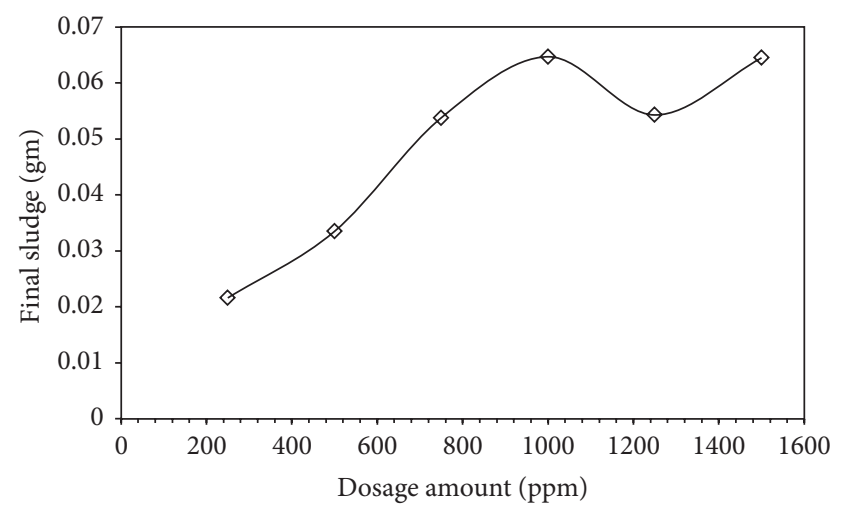

FIGURE 10: Sludge accumulation at different coagulant dosage.

have met the requirements of the Malaysian environmental standard "B" of the effluent quality, which is below $100 \mathrm{mg} / \mathrm{L}$ of COD. Addition of $4 \mathrm{~mL}$ of $\mathrm{H}_{2} \mathrm{O}_{2}$ to $100 \mathrm{~mL}$ wastewater was found to be the best in COD removal, but all other values are still at an acceptable level since it passes the requirement of the effluent standard. The percentage of color removal at different dosage of hydrogen peroxide is shown in Figure 12. The addition of $\mathrm{H}_{2} \mathrm{O}_{2}$ has resulted in more than $99 \%$ of color removal from the wastewater. The $\mathrm{COD}$ removal trend is decreasing from $1 \mathrm{~mL} \mathrm{H}_{2} \mathrm{O}_{2}$ dosage to $3 \mathrm{~mL} \mathrm{H}_{2} \mathrm{O}_{2}$ dosage but increased again as the $\mathrm{H}_{2} \mathrm{O}_{2}$ dosage raises up from $4 \mathrm{~mL}$ to $6 \mathrm{~mL}$. This created a $\mathrm{U}$ shape graph, with $3 \mathrm{~mL}$ of $\mathrm{H}_{2} \mathrm{O}_{2}$ recorded the lowest COD removal. COD removal with more than $99 \%$ removal is considered very high, as the color of the effluent is very clear.

From Figure 13, we can see that the effluent from the secondary treatment is very acidic, with the value recorded of $\mathrm{pH}$ 2.4. This phenomenon can be explained by the Fenton's reaction between $\mathrm{H}_{2} \mathrm{O}_{2}$ and ferrous or ferric ions as shown in (1) and (2):

$$
\begin{aligned}
& \mathrm{Fe}^{2+}+\mathrm{H}_{2} \mathrm{O}_{2} \longrightarrow \mathrm{Fe}^{3+}+\mathrm{OH}^{\bullet}+\mathrm{OH}^{-} \\
& \mathrm{Fe}^{3+}+\mathrm{H}_{2} \mathrm{O}_{2} \longrightarrow \mathrm{Fe}^{2+}+\mathrm{OOH}^{\bullet}+\mathrm{H}^{+}
\end{aligned}
$$


TABLE 2: Comparison of results of a prior research and this study of the removal of Eriochrome Blue Black.

\begin{tabular}{lccc}
\hline Dye concentration Color removal\% & Method & Reference \\
\hline $150 \mathrm{mg} / \mathrm{L}$ & 92.5 & Fluorescein degradation by hydrogen peroxide and biocatalyst & Pirillo et al., 2009 [17] \\
$400 \mathrm{mg} / \mathrm{L}$ & 94 & Coagulation using alum coagulant with lime & Rashidi and Eldemerdash, 2012 [18] \\
$400 \mathrm{mg} / \mathrm{L}$ & 96.5 & Coagulation using ferrous sulfate & This study \\
$400 \mathrm{mg} / \mathrm{L}$ & 99.89 & Combined coagulation and AOPs & This study \\
\hline
\end{tabular}

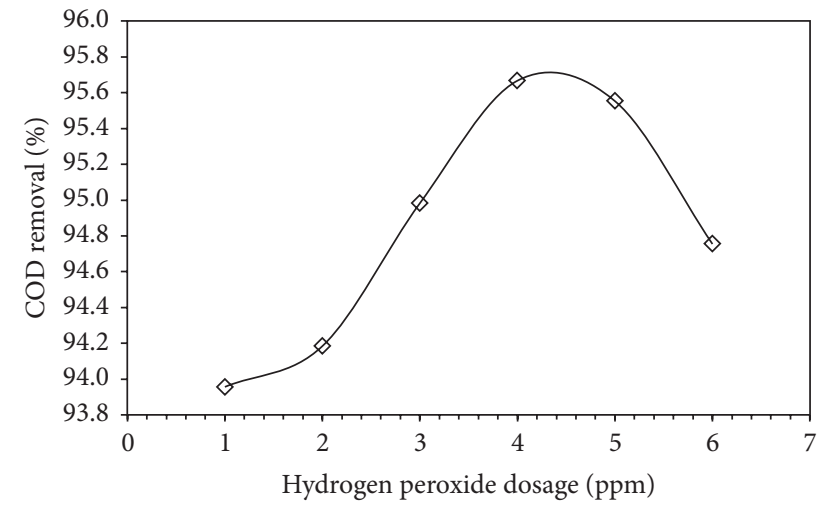

Figure 11: Percentage of COD removal at different dosage of hydrogen peroxide.

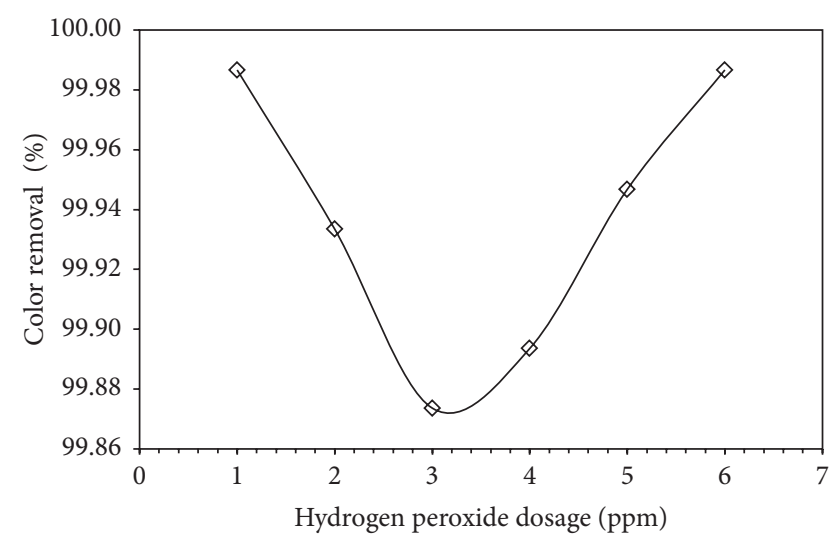

FIGURE 12: Percentage of color removal at different dosage rates of hydrogen peroxide.

where the reaction produced $\left(\mathrm{OOH}^{\circ}\right)$ compound can further react with other elements to form acids, which gives the acidic characteristic to the effluent. These active groups, that result from reactions shown in (1) and (2), are responsible for reacting with the organic compound of the dye stuff which results in the reduction of COD and color. Table 2 shows a comparison of results in a previous research and this study of the removal of Eriochrome Blue Black.

\section{Conclusion}

The first step of the proposed integrated treatment was made using the coagulation process employing ferrous sulfate. This step was applied with high efficiency for the removal of azo

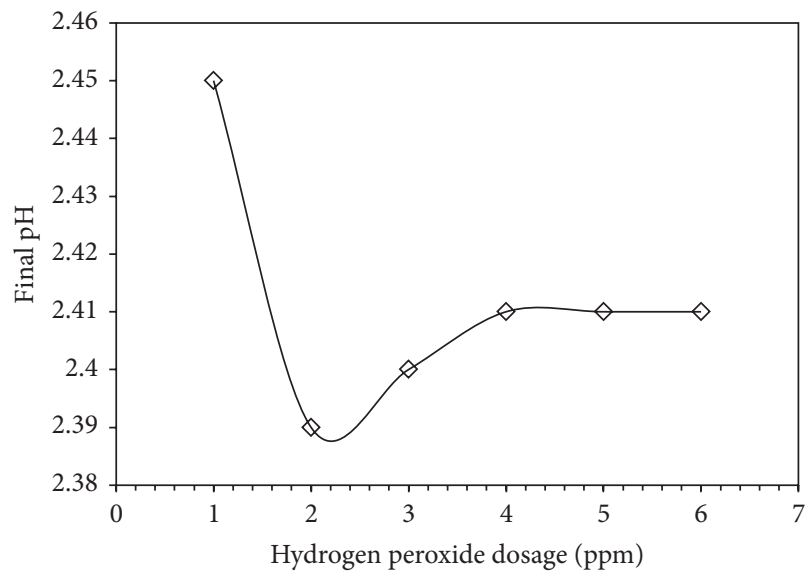

FIgURE 13: Percentage of final $\mathrm{pH}$ at different dosage rates of hydrogen peroxide.

dyes such as Eriochrome Black $\mathrm{T}$ at optimum conditions; the optimum concentration of coagulant (ferrous sulfate) dosage was $1000 \mathrm{ppm}$ for water contaminated with $400 \mathrm{ppm}$ of Eriochrome Black T. The optimum initial $\mathrm{pH}$ is 10 and the optimum temperature for the treatment process is (21$23^{\circ} \mathrm{C}$ ), with higher temperature that may result in lower COD and color removal. The combination of $1000 \mathrm{ppm}$ of ferrous sulfate dosage with $\mathrm{pH} 10$ and room temperature results in 96.53\% color removal and 76.17 COD removal from water contaminated with $400 \mathrm{ppm}$ of Eriochrome Black T. The second step of the proposed integrated treatment of Fenton process was completed successfully, which resulted in more than $99 \%$ of color removal from the wastewater and COD removal with more than $99 \%$ removal. The advantage of this method is the breakthrough removal of color and COD without usage of an external catalyst for the Fenton process. Additionally, Fenton process was done at minimal dosage of hydrogen peroxide which represents attractive environmental and healthy approach together with expected economic benefits. The results suggest that the method is effective in the removal of azo dyes from the aqueous environment.

\section{Conflict of Interests}

The authors declare that there is no conflict of interests regarding the publication of this paper. 


\section{References}

[1] M. C. Venceslau, S. Tom, and J. J. Simon, "Characterization of textile wastewater: a review," Environmental Technology, vol. 15, pp. 917-929, 1994.

[2] D.-H. Ahn, W.-S. Chang, and T.-I. Yoon, "Dyestuff wastewater treatment using chemical oxidation, physical adsorption and fixed bed biofilm process," Process Biochemistry, vol. 34, no. 5, pp. 429-439, 1999.

[3] S.-F. Kang, C.-H. Liao, and M.-C. Chen, "Pre-oxidation and coagulation of textile wastewater by the Fenton process," Chemosphere, vol. 46, no. 6, pp. 923-928, 2002.

[4] A. Adel, I. Azni, S. Katayon, and T. G. Chuah, "Treatment of textile wastewater by advanced oxidation process: a review," Global NEST, vol. 6, pp. 222-230, 2004.

[5] M. A. Abu Hassan, T. P. Li, and Z. Z. Noor, "Coagulation and flocculation treatment of waste water in textile industry using chitosan," Journal of Chemical and Natural Resources Engineering 2008, vol. 4, no. 1, pp. 43-53.

[6] H. J. H. Fenton, "Oxidation of tartaric acid in presence of iron," Journal of the Chemical Society, Transactions, vol. 65, pp. 899910, 1894.

[7] C. Walling and S. Kato, "The oxidation of alcohols by Fenton's reagent: the effect of copper ion," Journal of the American Chemical Society, vol. 93, pp. 4275-4280, 1971.

[8] W. G. Kuo, "Decolorizing dye wastewater with Fenton's reagent," Water Research, vol. 26, no. 7, pp. 881-886, 1992.

[9] E. G. Solozhenko, N. M. Soboleva, and V. V. Goncharuk, "Decolourization of azodye solutions by Fenton's oxidation," Water Research, vol. 29, no. 9, pp. 2206-2210, 1995.

[10] S. H. Lin and C. C. Lo, "Fenton process for treatment of desizing wastewater," Water Research, vol. 31, no. 8, pp. 2050-2056, 1997.

[11] S.-F. Kang, C.-H. Liao, and M.-C. Chen, "Pre-oxidation and coagulation of textile wastewater by the Fenton process," Chemosphere, vol. 46, no. 6, pp. 923-928, 2002.

[12] H. Gulyas, "Processes for the removal of recalcitrant organics from industrial wastewaters," Water Science and Technology, vol. 36, no. 2-3, pp. 9-16, 1997.

[13] OSHA, "Occupational Safety and Health Standards: Toxic and Hazardous Substances, Standard Number 1910. 1000 table Z-1, table Z-1 Limits for Air Contaminants," https://www.osha.gov/ pls/oshaweb/owadisp.show_document?p_table=standards\&p_ id $=10099$

[14] OSHA, "Occupational Safety and Health Guideline for Hydrogen Peroxide," https://www.osha.gov/dts/chemicalsampling/ data/CH_246600.html

[15] "Final opinion of the scientific committee on cosmetic products and non-food products intended for consumers concerning hydrogen (carbamide, zinc) peroxide in tooth bleaching/whitening products," Tech. Rep. SCCNFP/0602/02, Adopted by the SCCNFP during the 21st plenary meeting of 17 September 2002.

[16] P. Nigam and P. Ashok, Biotechnology for Agro-Industrial Residues Utilization, Springer, 2000.

[17] S. Pirillo, M. L. Ferreira, and E. H. Rueda, "The effect of $\mathrm{pH}$ in the adsorption of Alizarin and Eriochrome Blue Black R onto iron oxides," Journal of Hazardous Materials, vol. 168, no. 1, pp. 168-178, 2009.

[18] N. A. Rashidi and U. M. N. Eldemerdash, "Evaluation of Lime as an aid for coagulation: flocculation treatment of textile wastewater effluent," InterCeram: International Ceramic Review, vol. 61, no. 1, pp. 12-15, 2012.
[19] C. Galindo and A. Kalt, "UV- $\mathrm{H}_{2} \mathrm{O}_{2}$ oxidation of monoazo dyes in aqueous media: a kinetic study," Dyes and Pigments, vol. 40, no. 1, pp. 27-35, 1999. 

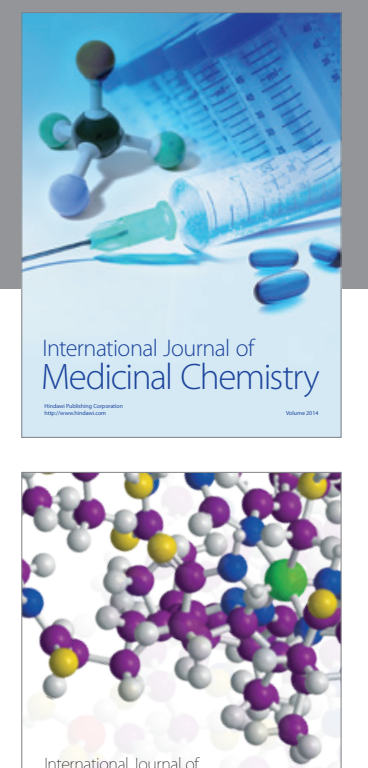

\section{Carbohydrate} Chemistry

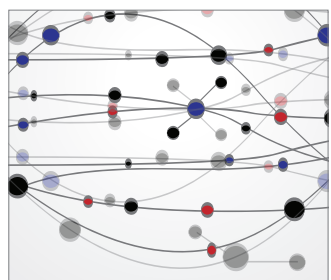

The Scientific World Journal
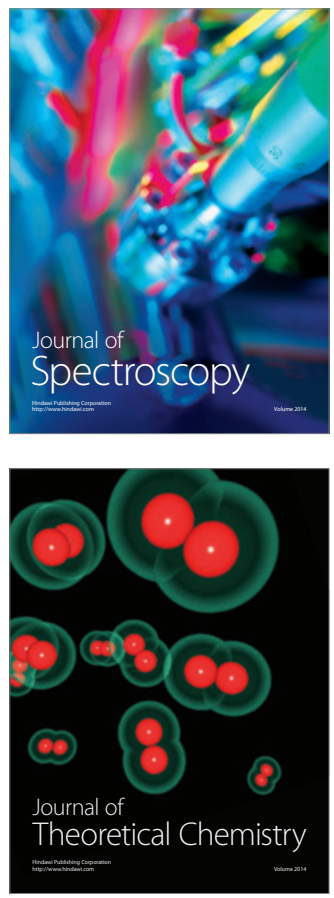
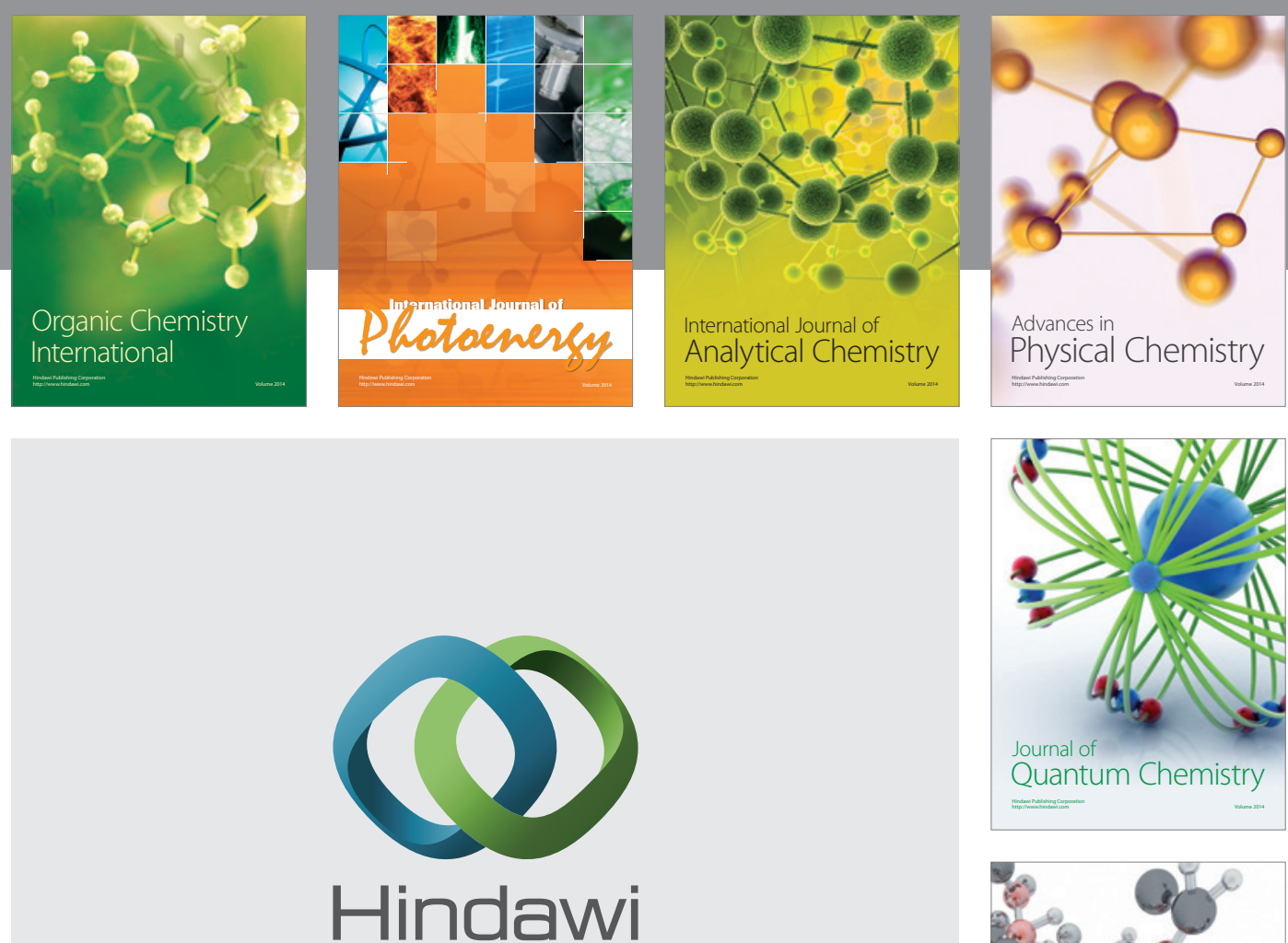

Submit your manuscripts at

http://www.hindawi.com

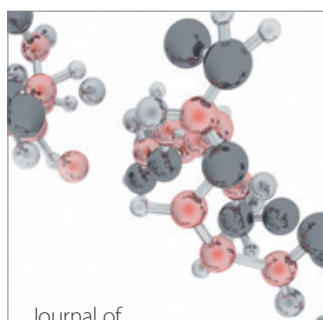

Analytical Methods

in Chemistry

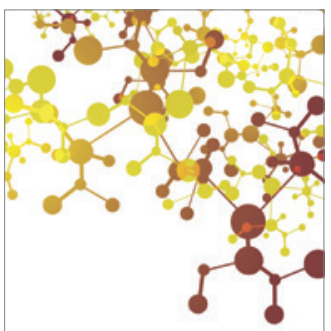

Journal of

Applied Chemistry

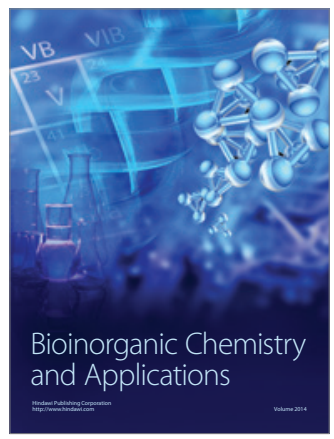

Inorganic Chemistry
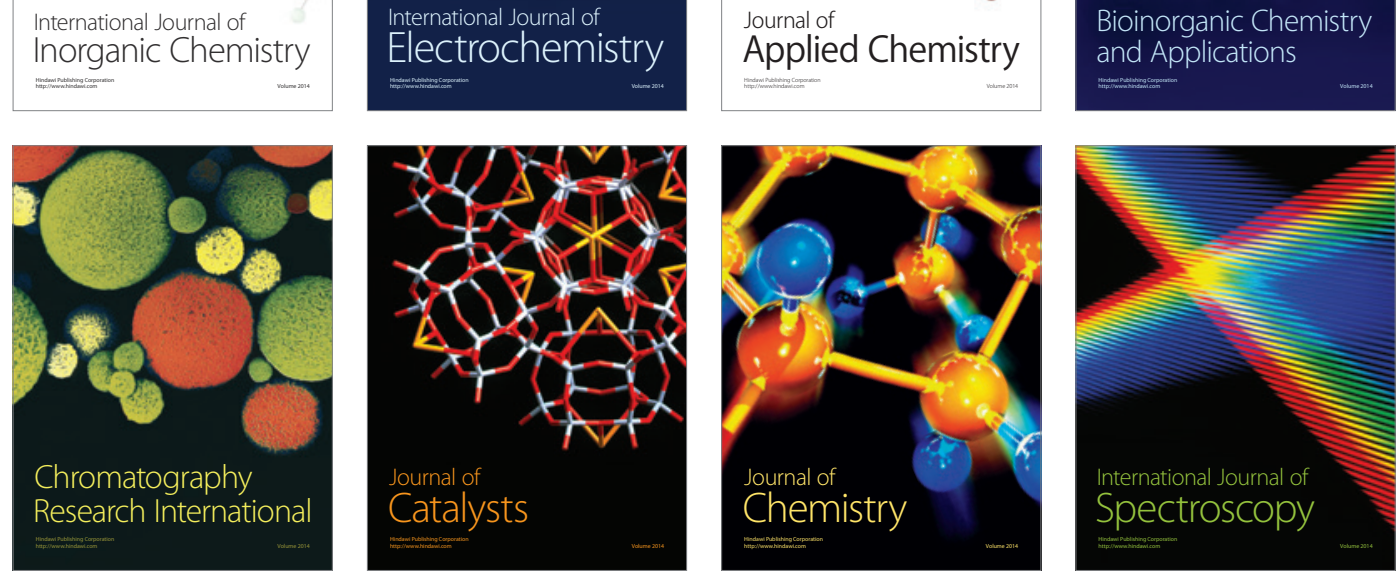